\title{
Weedborne Reservoirs and Seed Transmission of Verticillium dahliae in Lettuce
}

Gary E. Vallad, Department of Plant Pathology, University of California, Davis, c/o United States Agricultural Research Station (USARS), Salinas 93905; Ravi G. Bhat, Department of Plant Pathology, University of California, Davis, 95616; Steven T. Koike, University of California Cooperative Extension, Salinas 93901; Edward J. Ryder, Agricultural Research Service, United States Department of Agriculture, USARS, Salinas; and Krishna V. Subbarao, Department of Plant Pathology, University of California, Davis, c/o USARS, Salinas

\begin{abstract}
Vallad, G. E., Bhat, R. G., Koike, S. T., Ryder, E. J., and Subbarao, K. V. 2005. Weedborne reservoirs and seed transmission of Verticillium dahliae in lettuce. Plant Dis. 89:317-324.

The seed transmission of Verticillium dahliae was evaluated in lettuce (Lactuca sativa). Seed collected from lettuce plants infected with $V$. dahliae were plated with or without surface sterilization on Sorenson's modified NP10 medium. Of the seed plated with or without surface sterilization, 90 and $66 \%$, respectively, yielded colonies of $V$. dahliae. The incidence of Verticillium wilt ranged from 55 to $80 \%$ among lettuce plants grown from seed harvested from infected plants. All evaluated isolates of $V$. dahliae were capable of seed transmission in lettuce. A $V$. tricorpus isolate failed to cause significant disease in lettuce or to become seedborne. Storage of contaminated seed at seven temperatures ranging from -20 to $15^{\circ} \mathrm{C}$ for up to 72 weeks did not reduce the incidence of $V$. dahliae in seed, whereas storage at room temperature $\left(23 \pm 2^{\circ} \mathrm{C}\right)$ for 20 to 52 weeks reduced the incidence of $V$. dahliae without affecting seed viability. Of the 11 weed species collected from fields with a known history of Verticillium wilt of lettuce, four yielded $V$. dahliae. Pathogenicity tests demonstrated that isolates of $V$. dahliae from Sonchus oleraceus, Capsella bursa-pastoris, and Solanum sarrachoides were as virulent as or more virulent than an isolate of $V$. dahliae from lettuce. These results demonstrate the potential of seedborne and weedborne inoculum to disseminate $V$. dahliae.
\end{abstract}

Verticillium wilt that occurs on many dicotyledonous plants is predominantly caused by the soilborne pathogens Verticillium dahliae Kleb. and V. albo-atrum Reinke \& Berthold. Both pathogens colonize xylem tissues and cause disease on a broad array of plants (19). In some instances, these vascular pathogens may even invade the inflorescence and, subsequently, the developing fruit and seed $(1,10,11,24)$. A third species, V. tricorpus, also is common to soil, but only considered a minor plant pathogen compared with $V$. dahliae and $V$. albo-atrum $(19,28)$. All three fungi exhibit similar mycelium morphology. $V$. dahliae is distinguishable from $V$. albo-atrum by the presence of microsclerotia and the absence of highly melanized resting mycelia, whereas $V$. albo-atrum only produces melanized mycelia (28). V. tricorpus is distinguished by its capability to produce microsclerotia, melanized resting mycelia, and chlamydospores (28). The microsclerotia produced by $V$. dahliae serve as resting structures that are capable of surviving in soil under field conditions for up to 14

Corresponding author: K. V. Subbarao

E-mail: kvsubbarao@ucdavis.edu

Accepted for publication 29 October 2004.

DOI: 10.1094/PD-89-0317

(C) 2005 The American Phytopathological Society years in the absence of a host, making it a particularly difficult pathogen to control without the use of soil fumigants (36).

Wilts caused by $V$. dahliae have become a major problem in the cool-season production areas of coastal California over the past 10 years. $V$. dahliae is a prominent pathogen of a number of vegetable crops grown in the area $(3,12)$, including those once considered nonhosts, such as lettuce (33). Few pathogens exhibit as diverse a host range as $V$. dahliae (14). Complicating this further is that many isolates of $V$. dahliae are also cross-pathogenic, capable of causing a range of symptom severities on several hosts $(2,32)$. These individual isolates are usually most virulent on the host of origin. However, some are more host specialized and exhibit a limited host range (2). Cross-pathogenicity gives $V$. dahliae isolates the ability to persist within a field on hosts grown in rotation with lettuce and, potentially, on weed species susceptible to Verticillium wilt that are present within the production field or the surrounding noncultivated areas.

Verticillium wilt on lettuce (L. sativa $\mathrm{L}$.) was identified in 1995 on a single ranch in coastal California and since has spread to other major lettuce production areas of this region (31). All market types of lettuce (i.e., head, leaf, romaine, and butter) are susceptible, although considerable variability exists in the degree of susceptibility among the lettuce types (33). A unique aspect of the disease on lettuce has been the association of an unusually high number of microsclerotia per gram of soil and wilt incidence. Nearly all fields that suffered extensive crop losses have contained between 200 and 2,500 microsclerotia $\mathrm{g}^{-1}$ of dry soil (31) in contrast to the range of 20 to 80 microsclerotia $\mathrm{g}^{-1}$ of dry soil described for a field continuously cropped with cotton for 7 years (20). Another unique feature of the lettuce crop itself and, consequently, of Verticillium wilt on lettuce is that lettuce is harvested in its vegetative stage when the disease also occurs. In most other crops, the disease is most severe when the crops are in the reproductive phase.

Although the modes of spread of $V$. dahliae are well defined in the literature (19), the unique aspects of the disease on lettuce require a reexamination of the pathogen transmission. Furthermore, even if the modes of transmission in lettuce are similar to those previously described in the literature, the duration of persistence of the seedborne inoculum has never been examined. The objectives of the present work were to (i) demonstrate the seedborne nature of $V$. dahliae in lettuce, (ii) assess the survival of $V$. dahliae in lettuce seed, and (iii) examine the potential of weed species common to lettuce production areas in central California to harbor isolates of $V$. dahliae pathogenic to lettuce.

\section{MATERIALS AND METHODS}

Lettuce plants and Verticillium isolates. Seed of the lettuce cv. Salinas and plant introduction (PI) 120938 were sown into autoclaved sand $\left(1 \mathrm{~h}\right.$ at $\left.121^{\circ} \mathrm{C}\right)$ in 200 well seedling trays and maintained in the greenhouse $\left(23 \pm 5^{\circ} \mathrm{C}\right.$ with ambient light $)$ until needed. Isolates of $V$. dahliae from lettuce and artichoke (Cynara scolymus L.), and an isolate of $V$. tricorpus Isaac from artichoke (Table 1) were used to assess the seedborne nature of the pathogen in lettuce. Isolates were recovered (VdLs.17 in 1996 and the remaining isolates in 1998) from the roots of symptomatic plants in commercial fields in the Salinas and Pajaro Valleys, CA. Isolates were subcultured from single spores and stored on potato dextrose agar (PDA) slants at $4^{\circ} \mathrm{C}$. The identities of isolates were confirmed based on key morphological characteristics (28). 
Determination of the seedborne nature of $V$. dahliae in lettuce. Inoculum for isolates of $V$. dahliae from artichoke and lettuce was prepared from 3-week-old cultures on PDA. Conidia were collected from each isolate and adjusted to a final concentration of $10^{7}$ conidia $\mathrm{ml}^{-1}$ in sterile distilled water. Four-week-old seedlings of cv. Salinas were carefully removed and rinsed free of sand. Roots of the seedlings were trimmed $2 \mathrm{~cm}$ prior to dipping in suspensions of conidia for at least $5 \mathrm{~min}$. Individual plants then were transplanted into 0.5-liter (16-oz.) insulated foam cups filled with autoclaved sand. For each isolate, at least 10 plants were inoculated, and at least 10 plants were dipped in sterile distilled water and maintained as uninoculated controls. Plants were arranged in a completely randomized design and maintained in the greenhouse for 8 weeks prior to evaluation for disease development. Vascular discoloration of plant roots then was scored by longitudinally cutting from the crown through the taproots to expose vascular tissues. The severity of vascular discoloration was recorded using a scale of 0 to 5 , in which $0=$ no vascular discoloration, $1=1$ to $25,2=26$ to $50,3=51$ to 75 , and $4=76$ to $100 \%$ of vascular tissues exhibited discoloration in the absence of foliar symptoms; and $5=100 \%$ of vascular tissues exhibited discoloration and the wilting of foliar tissues typical of Verticillium wilt. The experiment was conducted twice. Analysis of variance was conducted to determine the overall effect of the $V$. dahliae isolates and $V$. tricorpus isolate on the severity of disease symptoms on lettuce. Replications within experiments were

Table 1. Severity of Verticillium wilt on lettuce plants (cv. Salinas) inoculated with isolates of Verticillium dahliae $(\mathrm{Vd})$ from lettuce and artichoke, and an isolate of V. tricorpus (Vt)

\begin{tabular}{llc}
\hline $\begin{array}{l}\text { Source of } \\
\text { isolate }\end{array}$ & Isolate $^{\mathbf{y}}$ & $\begin{array}{c}\text { Disease } \\
\text { severity }^{\mathbf{z}}\end{array}$ \\
\hline Lettuce & VdLs.17 & $5.0 \mathrm{a}$ \\
Artichoke & VdCs.208 & $4.0 \mathrm{a}$ \\
Artichoke & VdCs.212 & $2.8 \mathrm{~b}$ \\
Artichoke & VtCs.225 & $0.3 \mathrm{c}$ \\
$\ldots$ & Control & $0.0 \mathrm{c}$ \\
\hline
\end{tabular}

${ }^{y}$ Roots of 4-week-old seedlings were trimmed 2 $\mathrm{cm}$ and dipped into a $1 \times 10^{7}$ conidia $\mathrm{ml}^{-1}$ suspension for each isolate or dipped into sterile distilled water for the control, prior to transplanting. Plants were further maintained under greenhouse conditions for another 8 weeks.

${ }^{2}$ Mean disease severity of five plants was rated on a scale of 0 to 5 , in which $0=$ no vascular discoloration, $1=1$ to $25,2=26$ to $50,3=51$ to 75 , and $4=76$ to $100 \%$ of vascular tissues exhibited discoloration in the absence of foliar symptoms; and $5=100 \%$ of vascular tissues exhibited discoloration and the wilting of foliar tissues typical of Verticillium wilt. Experiment was conducted twice with similar results. Values followed by the same letter are not significantly different based on the least significant difference test $(P=0.05)$. considered random effects in the analysis. The mean disease severity was calculated for each isolate and comparisons among isolates were made using Fisher's protected least significant difference test $(P \leq$ 0.05).

Several of the uninoculated and inoculated plants from the above experiments were further maintained in the greenhouse to produce seed. Viable and nonviable seed and pericarp (made up of sclerenchyma and parenchyma) surrounding seed from inoculated and uninoculated plants were collected at maturity. Twenty-five seed were placed onto a modified Sorenson's NP10 semi-selective medium $(9,30)$ either directly or following surface disinfestation with $70 \%$ ethyl alcohol for 20 s. Plates were incubated at room temperature $(23 \pm$ $2^{\circ} \mathrm{C}$ ) and monitored for 3 weeks for seed germination (occurring generally within the first week) and the emergence of $V$. dahliae and other fungal colonies from viable and nonviable seed and pericarp from seed. The experiment was conducted twice. The percentage of viable seed, nonviable seed, and pericarp that yielded colonies of $V$. dahliae either from direct plating or plating after surface disinfestation was calculated for lettuce.

Experiments testing for seed transmission of $V$. dahliae to developing seedlings and the subsequent development of symptoms also relied on seed collected from lettuce plants inoculated with isolates of $V$. dahliae and V. tricorpus, as previously described. Seedlings were grown and maintained as previously described, except that 4-week-old seedlings were directly transplanted to 0.5-liter (16-oz.) insulated foam cups, keeping the roots and adhering soil intact. Plants were arranged in a completely randomized design and maintained in the greenhouse for 8 weeks prior to evaluation for disease development. Vascular discoloration of plant roots then was scored by longitudinally cutting from the crown through the taproots to expose vascular tissues. The percentage of plants that exhibited symptoms matching one of six disease classes was recorded, in which $0=$ no vascular discoloration, $1=1$ to $25,2=$ 26 to $50,3=51$ to 75 , and $4=76$ to $100 \%$ of vascular tissues exhibited discoloration in the absence of foliar symptoms; and $5=$ $100 \%$ of vascular tissues exhibited discoloration and the wilting of foliar tissues typical of Verticillium wilt. The experiment was conducted twice.

Isolation of $\boldsymbol{V}$. dahliae from weeds. The initial survey of weeds as potential carriers of $V$. dahliae was conducted in the ranch where the disease was first discovered (33). A number of weeds from the ditch banks (where a very high concentration of $V$. dahliae microsclerotia $\left(2,500 \mathrm{~g}^{-1}\right.$ of dry soil] was found) and around the fields were collected and transported to the laboratory. The roots and stems of weeds along with seed from inflorescences, if available (only in the case of two Sonchus oleraceus L. plants), were washed with tap water, surface disinfested in a solution of $70 \%$ ethyl alcohol for $20 \mathrm{~s}$, and then thoroughly rinsed with sterile distilled water. Several excised pieces from surface-disinfested root and stem segments then were placed on a modified Sorenson's NP10 semiselective medium $(9,30)$. Plates were incubated for at least 3 weeks at room temperature $\left(23 \pm 2^{\circ} \mathrm{C}\right)$ and periodically monitored for the presence of mycelia and microsclerotia typical of $V$. dahliae. The number of weeds yielding colonies of $V$. dahliae was recorded and the weeds were identified to the species level. Several resulting colonies of $V$. dahliae were further purified by single-spore isolations. Purified isolates were stored on PDA slants at $4^{\circ} \mathrm{C}$ prior to their use in lettuce pathogenicity experiments. The identities of all isolates were confirmed based on key morphological characteristics (28).

A systematic survey was conducted from April to October of 2001 and 2002. Weed species identified during the preliminary surveys, as well as other weed species, were arbitrarily collected from the production fields and noncultivated areas bordering fields where Verticillium wilt previously was observed in both Santa Cruz and Monterey Counties in California. These plants also were processed as described above and the number of weed species yielding colonies of $V$. dahliae was recorded and isolates purified and stored.

Pathogenicity of isolates of $V$. dahliae from weeds on lettuce. Isolates of $V$. dahliae recovered from Capsella bursapastoris (L.) Medik, Senecio vulgaris L., Solanum sarrochoides Sendtner, and Sonchus oleraceus L. were evaluated for pathogenicity on lettuce. Inoculum for each isolate was prepared as previously described and the density was adjusted to $10^{7}$ conidia $\mathrm{ml}^{-1}$. Four-week-old lettuce seedlings (cv. Salinas) were carefully removed and rinsed to remove sand from roots. Roots were trimmed $2 \mathrm{~cm}$ prior to dipping in suspensions of conidia from each isolate for at least $5 \mathrm{~min}$. Individual plants then were transplanted into 0.5 -liter (16-oz.) foam insulated cups filled with autoclaved sand. For each isolate, five plants were inoculated. Another five plants were dipped in sterile distilled water and maintained as uninoculated controls. Plants were arranged in a completely randomized design and maintained in the greenhouse for 8 weeks prior to uprooting and washing free of soil. Vascular discoloration of plant roots then was scored by longitudinally cutting from the crown through the taproots to expose vascular tissues. The severity of vascular discoloration was recorded using a scale of 0 to 5 , in which $0=$ no vascular discoloration, $1=$ 1 to $25,2=26$ to $50,3=51$ to 75 , and $4=$ 76 to $100 \%$ of vascular tissues exhibited discoloration in the absence of foliar 
symptoms; and $5=100 \%$ of vascular tissues exhibited discoloration and the wilting of foliar tissues typical of Verticillium wilt. The experiment was conducted twice. Analysis of variance was conducted to determine the effect of isolates from weeds on the severity of Verticillium wilt symptoms on lettuce. Replications within experiments were considered random effects in the analysis. The mean disease severity was calculated for each isolate of $V$. dahliae and comparisons among isolates were made using Fisher's protected least significant difference test $(P \leq 0.05)$.

Effects of storage temperature on the viability of $\boldsymbol{V}$. dahliae in seed. Two seed lots infested with $V$. dahliae were produced by inoculating 4-week-old lettuce seedlings of PI 120938 with isolate VdLs.17. The plants were maintained in the greenhouse until seed set. The seed was harvested, cleaned, and used to assess the effects of storage temperature on the survival of $V$. dahliae in infested seed. Random samples of infested seed were drawn from both seed lots, surface disinfested with a solution of $70 \%$ ethyl alcohol as previously described, and plated on a modified NP10 medium $(9,30)$ to assess the degree of $V$. dahliae infestation. The plates were evaluated weekly for colonies of $V$. dahliae emerging from seed. Aliquots of seed $(5 \mathrm{~g})$ from each seed lot were placed in \#2 coin envelopes and incubated at $-20,-15,-10,0,5,10,15$, and $23^{\circ} \mathrm{C}$. Prior to incubating seed samples and every 2 to 4 weeks during the 72-week incubation, 21 seed from each incubation temperature of each seed lot were plated onto NP10 medium and monitored for germination and the emergence of $V$. dahliae and other fungi. The number of germinated seed and the number of seed yielding colonies of $\mathrm{V}$. dahliae or other fungi was expressed as a percentage and plotted against time.

\section{RESULTS}

Virulence of $\boldsymbol{V}$. dahliae isolates on lettuce. Lettuce plants (cv. Salinas) inoculated with isolates VdLs.17, VdCs.208, and VdCs.212 of $V$. dahliae exhibited mean disease severity ratings $>2$, whereas plants inoculated with the isolate of $V$. tricorpus, VtCs.225, exhibited a mean disease severity rating $<2$ (Table 1 ). No significant difference $(P \leq 0.05)$ in mean disease severity ratings was observed between isolates VdLs.17 and VdCs.208, even though they originated from different hosts. However, isolates VdLs.17 and VdCs.208 were significantly $(P \leq 0.05)$ more virulent than VdCs.212 from artichoke.

Seedborne nature of $\boldsymbol{V}$. dahliae in lettuce. Of the viable seed harvested from plants inoculated with $V$. dahliae, 44 to $100 \%$ yielded V. dahliae (Table 2). V. dahliae also was recovered from 77 to $100 \%$ of the nonviable seed. No Verticillium sp. was detected on seed and pericarps from plants inoculated with the isolate of $V$. tricorpus, VtCs.225, or uninoculated control plants. Surface disinfestation of nonviable seed did not have a significant effect on the recovery of $V$. dahliae, but improved recovery from viable seed. Overall, surface disinfestation of either viable or nonviable seed, or pericarps, drastically reduced the recovery of other fungi.

Of the plants grown from seed infested with $V$. dahliae, 55 to $80 \%$ developed symptoms of Verticillium wilt (Table 3 ). No significant difference was observed in the transmission of $V$. dahliae among plants grown from those seed collected from apical versus axillary capitula (flower heads) of infected lettuce plants based on the incidence of Verticillium wilt (data not shown). Plants grown from seed harvested from uninoculated control plants and from seed of plants inoculated with $V$. tricorpus, VtCs.225, did not exhibit symptoms of Verticillium wilt.

Weed hosts of $V$. dahliae. $V$. dahliae was recovered from 4 of 11 weed species tested (Table 4). All root and stem tissues plated on modified NP10 medium $(9,30)$

Table 2. Recovery of Verticillium dahliae and other fungi from seed and floral tissues of infected lettuce (cv. Salinas) plants

\begin{tabular}{|c|c|c|c|c|c|}
\hline \multirow[b]{2}{*}{ Verticillium isolate (source) ${ }^{\mathrm{y}}$} & \multirow[b]{2}{*}{ Tissue/seed sampled } & \multirow[b]{2}{*}{ Surface sterilization (total samples) $^{\mathrm{z}}$} & \multicolumn{3}{|c|}{ Percentage of seed contaminated ${ }^{x}$} \\
\hline & & & Verticillium & Other fungi & No fungi \\
\hline \multirow[t]{6}{*}{ VdLs.17 (lettuce) } & Viable seed & No (34) & 100 & 29 & 0 \\
\hline & & Yes (23) & 100 & 0 & 0 \\
\hline & Nonviable seed & No $(35)$ & 100 & 43 & 0 \\
\hline & & Yes (23) & 100 & 0 & 0 \\
\hline & Pericarp & No (22) & 68 & 95 & 0 \\
\hline & & Yes (19) & 74 & 26 & 21 \\
\hline \multirow[t]{6}{*}{ VdCs.208 (artichoke) } & Viable seed & No $(27)$ & 44 & 63 & 4 \\
\hline & & Yes (23) & 70 & 0 & 30 \\
\hline & Nonviable seed & No (31) & 81 & 26 & 0 \\
\hline & & Yes (26) & 77 & 0 & 23 \\
\hline & Pericarp & No (23) & 61 & 96 & 0 \\
\hline & & Yes (23) & 57 & 22 & 22 \\
\hline \multirow[t]{6}{*}{ VdCs.212 (artichoke) } & Viable seed & No (35) & 54 & 66 & 0 \\
\hline & & Yes (28) & 100 & 0 & 0 \\
\hline & Nonviable seed & No (33) & 100 & 27 & 0 \\
\hline & & Yes (35) & 86 & 3 & 11 \\
\hline & Pericarp & No (19) & 58 & 100 & 0 \\
\hline & & Yes (30) & 47 & 50 & 3 \\
\hline \multirow[t]{6}{*}{ VtCs.225 (artichoke) } & Viable seed & No $(26)$ & 0 & 100 & 0 \\
\hline & & Yes (26) & 0 & 0 & 100 \\
\hline & Nonviable seed & No (29) & 0 & 100 & 0 \\
\hline & & Yes (25) & 0 & 4 & 96 \\
\hline & Pericarp & No (23) & 0 & 100 & 0 \\
\hline & & Yes (28) & 0 & 11 & 89 \\
\hline \multirow[t]{6}{*}{ Control } & Viable seed & No (23) & 0 & 17 & 83 \\
\hline & & Yes (21) & 0 & 10 & 90 \\
\hline & Nonviable seed & No (21) & 0 & 86 & 14 \\
\hline & & Yes (21) & 0 & 24 & 76 \\
\hline & Pericarp & No $(21)$ & 0 & 90 & 10 \\
\hline & & Yes (21) & 0 & 14 & 86 \\
\hline
\end{tabular}


Table 3. Incidence and severity of Verticillium wilt in lettuce plants (cv. Salinas) grown from seed infested with Verticillium dahliae

\begin{tabular}{|c|c|c|c|c|c|c|c|c|}
\hline \multirow[b]{2}{*}{ Verticillium isolate $^{x}$} & \multirow[b]{2}{*}{ Germination (total seed) $)^{y}$} & \multirow[b]{2}{*}{ Disease incidence $(\%)^{\mathrm{z}}$} & \multicolumn{6}{|c|}{ Infected plants in each disease class $(\%)^{\mathrm{w}}$} \\
\hline & & & 0 & 1 & 2 & 3 & 4 & 5 \\
\hline VdLs.17 & $57(51)$ & 80 & 21 & 14 & 3 & 14 & 10 & 38 \\
\hline VdCs.208 & $46(24)$ & 55 & 45 & 9 & 9 & 9 & 9 & 18 \\
\hline VdCs. 212 & $43(70)$ & 63 & 37 & 10 & 7 & 0 & 27 & 20 \\
\hline VtCs.225 & 44 (39) & 0 & 100 & 0 & 0 & 0 & 0 & 0 \\
\hline Control & $78(27)$ & 0 & 100 & 0 & 0 & 0 & 0 & 0 \\
\hline
\end{tabular}

${ }^{w}$ Percentage of plants in two greenhouse experiments that exhibited symptoms matching one of six disease classes, in which $0=$ no vascular discoloration, 1

$=1$ to $25,2=26$ to $50,3=51$ to 75 , and $4=76$ to $100 \%$ of vascular tissues exhibited discoloration in the absence of foliar symptoms; and $5=100 \%$ of vascular tissues exhibited discoloration and the wilting of foliar tissues typical of Verticillium wilt. Values were rounded to the nearest whole number and may not total $100 \%$.

${ }^{\mathrm{x}}$ Lettuce seed infested with individual $V$. dahliae $(\mathrm{Vd})$ isolates or a $V$. tricorpus $(\mathrm{Vt})$ isolate were collected from greenhouse-grown plants that originally were inoculated as 4-week-old seedlings. Roots of seedlings were trimmed $2 \mathrm{~cm}$ and dipped into a $1 \times 10^{7}$ conidia ml ${ }^{-1}$ suspension for each isolate or dipped into sterile distilled water for the control, prior to transplanting.

y Percentage of total seed from plants that germinated in two greenhouse experiments.

${ }^{\mathrm{z}}$ Percentage of plants in two greenhouse experiments that exhibited root discoloration typical of Verticillium wilt.

Table 4. Isolation of Verticillium dahliae from weeds collected from lettuce production areas in central California with a history of Verticillium wilt

\begin{tabular}{llcc}
\hline Botanical name & Common name & Plants tested & $\begin{array}{c}\text { V. dahliae-infested } \\
(\%) \mathbf{z}\end{array}$ \\
\hline Capsella bursa-pastoris (L.) Medik & Shepherd's purse & 4 & 100 \\
Solanum sarrachoides Sendtner & Hairy nightshade & 2 & 100 \\
Sonchus oleraceus L. & Sowthistle & 27 & 32 \\
Senecio vulgaris L. & Groundsel & 5 & 20 \\
Raphanus sativus L. & Wild radish & 2 & 0 \\
Amaranthus hybridus L. & Pigweed & 2 & 0 \\
Chenopodium album L. & Lambsquarters & 1 & 0 \\
Conyza canadensis (L.) Cronq. & Mares tail & 1 & 0 \\
Xanthium spinosum L. & Spiny clotbur & 1 & 0 \\
Polygonum lapathifolium L. & Curlytop knotweed & 1 & 0 \\
Lactuca serriola L. & Wild lettuce & 1 & 0 \\
\hline
\end{tabular}

z Percentage of plants sampled from which $V$. dahliae was recovered when placed on a modified Sorenson's NP10 medium.

yielded $V$. dahliae. Of the 11 weed species sampled from fields or areas bordering those fields with a history of Verticillium wilt of lettuce, sowthistle was the most predominant. About $32 \%$ of the sampled sowthistle plants yielded colonies of $V$. dahliae. Seed collected from the inflorescences of two sowthistle plants also yielded colonies of $V$. dahliae. The other 10 species of weeds were not as numerically represented as sowthistle, reflecting their relative abundance during sampling, but many still yielded colonies of $V$. dahliae.

Pathogenicity of $V$. dahliae isolates from weeds on lettuce. Of the 11 isolates of $V$. dahliae tested from various weeds, 3 isolates (VdSo.428, VdCb.487, and VdSs.495) were as virulent as the representative isolate from lettuce, VdLs.17, and one isolate (VdSs.494) was more virulent than VdLs.17 (Table 5). Lettuce plants inoculated with the remaining seven isolates exhibited mean disease severity ratings $<2$ and were considered nonpathogenic on lettuce.

Effects of storage temperature on the viability of $\boldsymbol{V}$. dahliae in seed. At the onset of the experiment, the two seed lots composed of seed naturally infested with $V$. dahliae did not significantly differ with respect to seed germination $(t$ test; $P=$ $0.68)$. Seed sampled from lot 1 exhibited a lower incidence of $V$. dahliae $(t$ test; $P \leq$
0.001) and a higher incidence of other fungi ( $t$ test; $P \leq 0.001$ ) compared with seed sampled from lot 2 . However, the effect of the different storage temperatures over time on the survival of $V$. dahliae in seed was similar for both seed lots (Figs. 1 and 2). Seed germination within each seed lot remained relatively unchanged until week 56, when the germination for seed stored at ambient room temperature $\left(23^{\circ} \mathrm{C}\right)$ began to decline in both seed lots. Recovery of $V$. dahliae also showed a decline after 16 to 20 weeks of storage at $23^{\circ} \mathrm{C}$ in both seed lots. At all other temperatures, the recovery of $V$. dahliae from seed remained high, from 10 to $71 \%$ and 57 to $100 \%$ for lots 1 and 2, respectively. Data collection for both seed lots stored at $15^{\circ} \mathrm{C}$ was discontinued after 40 weeks, when the seed was inadvertently exposed to water while in storage.

Recovery of fungi other than $V$. dahliae varied little for either seed lot over the 68 to 72 weeks of storage across the different temperatures, except in seed stored at $23^{\circ} \mathrm{C}$ (Figs. 1 and 2). In lot 1 , there was a noticeable increase in the incidence of other fungi (non-Verticillium spp.) in seed stored at $23^{\circ} \mathrm{C}$ compared with seed stored at other temperatures from 20 to 52 weeks. A similar increase in the incidence of other fungi occurred in seed from lot 2 stored at $23^{\circ} \mathrm{C}$ from 48 to 68 weeks. In both instances, the
Table 5. Severity of Verticillium wilt on lettuce plants (cv. Salinas) inoculated with several isolates of Verticillium dahliae collected from weeds

\begin{tabular}{llc}
\hline Source of isolate & Isolate $^{\mathbf{y}}$ & $\begin{array}{c}\text { Disease } \\
\text { severity }^{\mathbf{z}}\end{array}$ \\
\hline Groundsel & VdSv.449 & $0.4 \mathrm{c}$ \\
Hairy nightshade & VdSs.494 & $5.0 \mathrm{a}$ \\
Hairy nightshade & VdSs.495 & $4.0 \mathrm{a}$ \\
Lettuce & VdLs.17 & $2.6 \mathrm{~b}$ \\
Shepherd's purse & VdCb.486 & $0.4 \mathrm{c}$ \\
Shepherd's purse & VdCb.487 & $2.2 \mathrm{~b}$ \\
Sowthistle & VdSo.428 & $2.2 \mathrm{~b}$ \\
Sowthistle & VdSo.451 & $0.4 \mathrm{c}$ \\
Sowthistle & VdSo.452 & $0.4 \mathrm{c}$ \\
Sowthistle & VdSo.493 & $0.6 \mathrm{c}$ \\
Sowthistle & VdSo.503 & $0.0 \mathrm{c}$ \\
Sowthistle & VdSo.504 & $0.2 \mathrm{c}$ \\
$\ldots$ & Control & $0.0 \mathrm{c}$ \\
\hline
\end{tabular}

y Roots of 4-week-old seedlings were trimmed 2 $\mathrm{cm}$ and dipped into a $1 \times 10^{7}$ conidia $\mathrm{ml}^{-1}$ suspension for each isolate or dipped into sterile distilled water for the control, prior to transplanting. Plants were further maintained under greenhouse conditions for another 8 weeks.

${ }^{\mathrm{z}}$ Mean disease severity of 5 plants rated using a scale of 0 to 5 , in which $0=$ no vascular discoloration, $1=1$ to $25,2=26$ to $50,3=51$ to 75 , and $4=76$ to $100 \%$ of vascular tissues exhibited discoloration in the absence of foliar symptoms; and $5=100 \%$ of vascular tissues exhibited discoloration and the wilting of foliar tissues typical of Verticillium wilt. Experiment was repeated twice with similar results. Values followed by the same letter are not significantly different based on the least significant difference test $(P=0.05)$.

increase in other fungi corresponded with the decrease in the percentage of seed contaminated with $V$. dahliae.

\section{DISCUSSION}

The seedborne nature of $V$. dahliae has been documented in cotton (1), eggplant, tomato (10), and spinach (29), and in the cultivated composites safflower and sunflower $(19,24,26,37)$. We report the seedborne nature of $V$. dahliae in lettuce under greenhouse conditions. All isolates of $V$. dahliae inoculated to lettuce were capable of seed transmission, regardless of the 
A

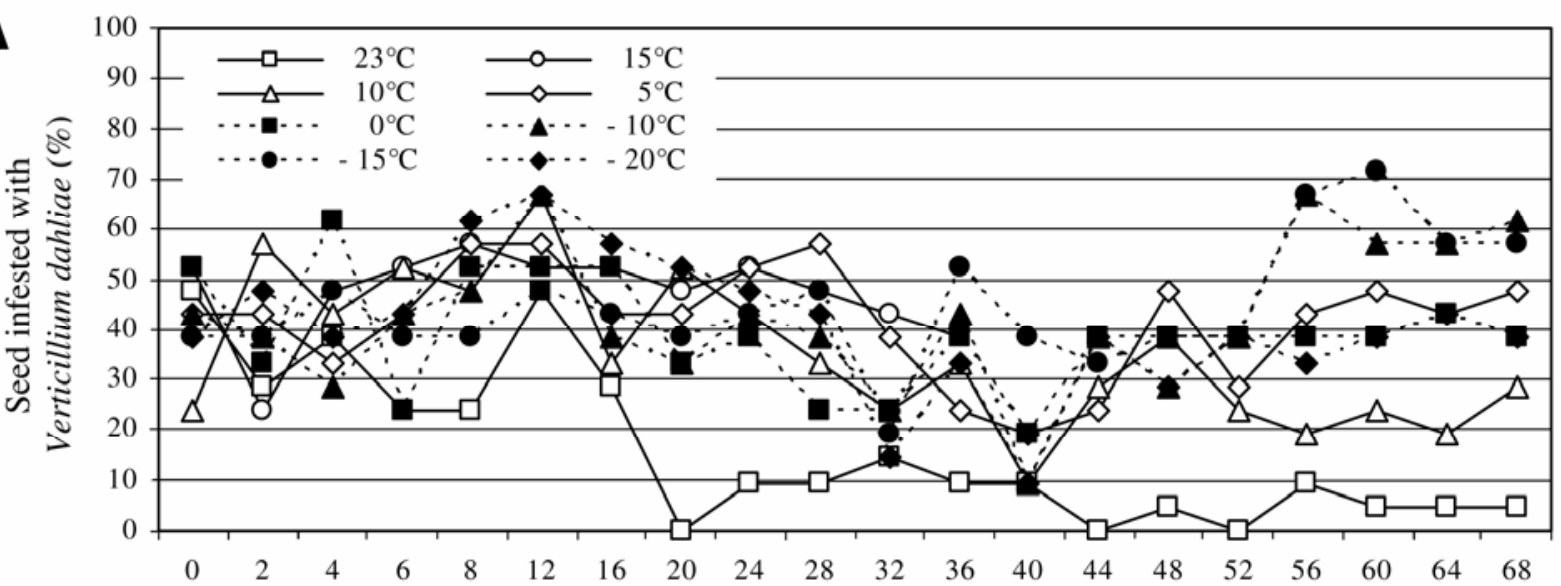

B

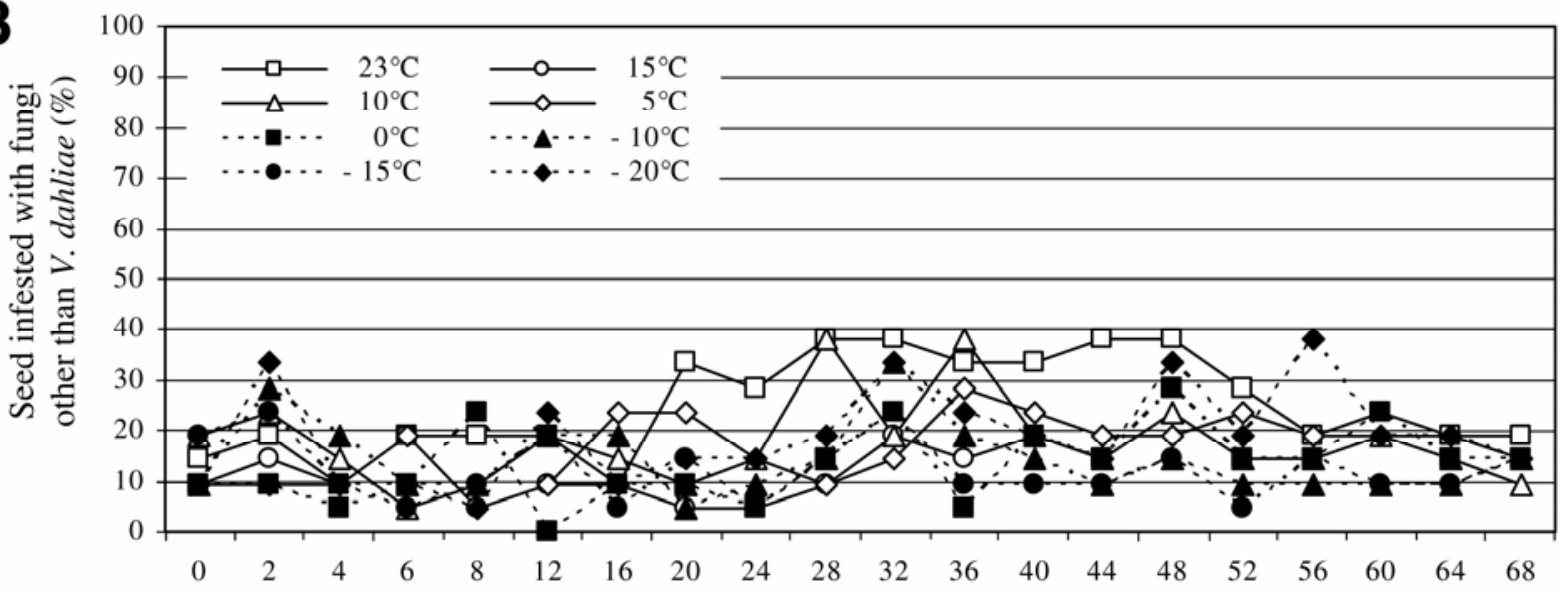

C

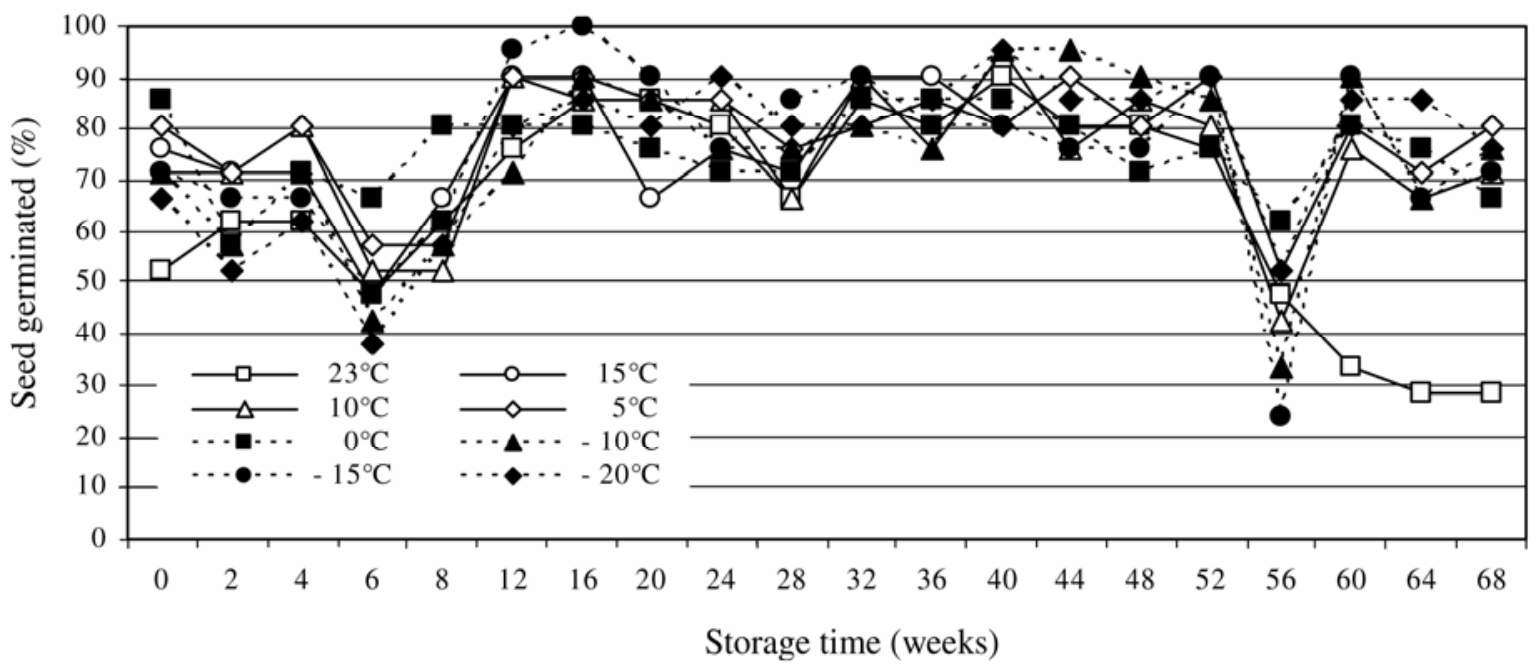

Fig. 1. Effect of storage temperature on the recovery of A, Verticillium dahliae and $\mathbf{B}$, other fungi from seed, and $\mathbf{C}$, seed germination in seed lot 1 . Over a 68-week period, the percentage of seed $(n=21)$ sampled from seed lot 1 that exhibited colonies of $V$. dahliae and other fungi and germination was determined by plating seed onto a modified Sorenson's NP10 medium. Seed storage at $23^{\circ} \mathrm{C}$ was performed at ambient room temperature $\left( \pm 2^{\circ} \mathrm{C}\right)$, whereas other storage temperatures were performed in controlled incubators. Data collection for seed stored at $15^{\circ} \mathrm{C}$ was discontinued after 40 weeks due to an accidental exposure of the seed to water while in storage.

relative virulence of the isolate or whether the isolate originated from lettuce or artichoke. The minor wilt pathogen, V. tricorpus (VtCs.225), failed to inflict significant disease symptoms on lettuce or to contaminate seed in inoculated plants (19). This is the first report of seed transmission of V. dahliae in L. sativa, which previously was reported to be a new host of $V$. dahliae $(15,33)$.

The recovery of $V$. dahliae from infested seed and floral tissues was aided by surface disinfestation, most likely by reducing the presence of competing fungi on the seed or tissue surface. The recovery of $V$. dahliae following the disinfestation of seed surfaces suggests that the fungus resides within the achene, similar to findings in safflower and sunflower $(11,24)$. In preliminary studies, the pericarps shed from germinating lettuce seed were colo- 
nized by $V$. dahliae, although whether any internal tissues are colonized remains unknown (G. E. Vallad and K. V. Subbarao, unpublished data). The shed pericarp from a germinating lettuce seed generally remains near the developing root system and could contain sufficient inoculum to facili- tate infection of the developing plants. In safflower and sunflower, where $V$. dahliae was confined to the pericarp and outer surface of the testa of infected seed, the pathogen never entered the testa $(11,24)$.

Our studies determined that $V$. dahliae can survive in lettuce seed for prolonged periods of time, especially when seed is stored at temperatures below $15^{\circ} \mathrm{C}$. Other researchers also have reported on the survival of Verticillium spp. in infested seed over extended durations. Sackston and Martens (24) noted that V. dahliae survived in naturally infested sunflower seed for 16

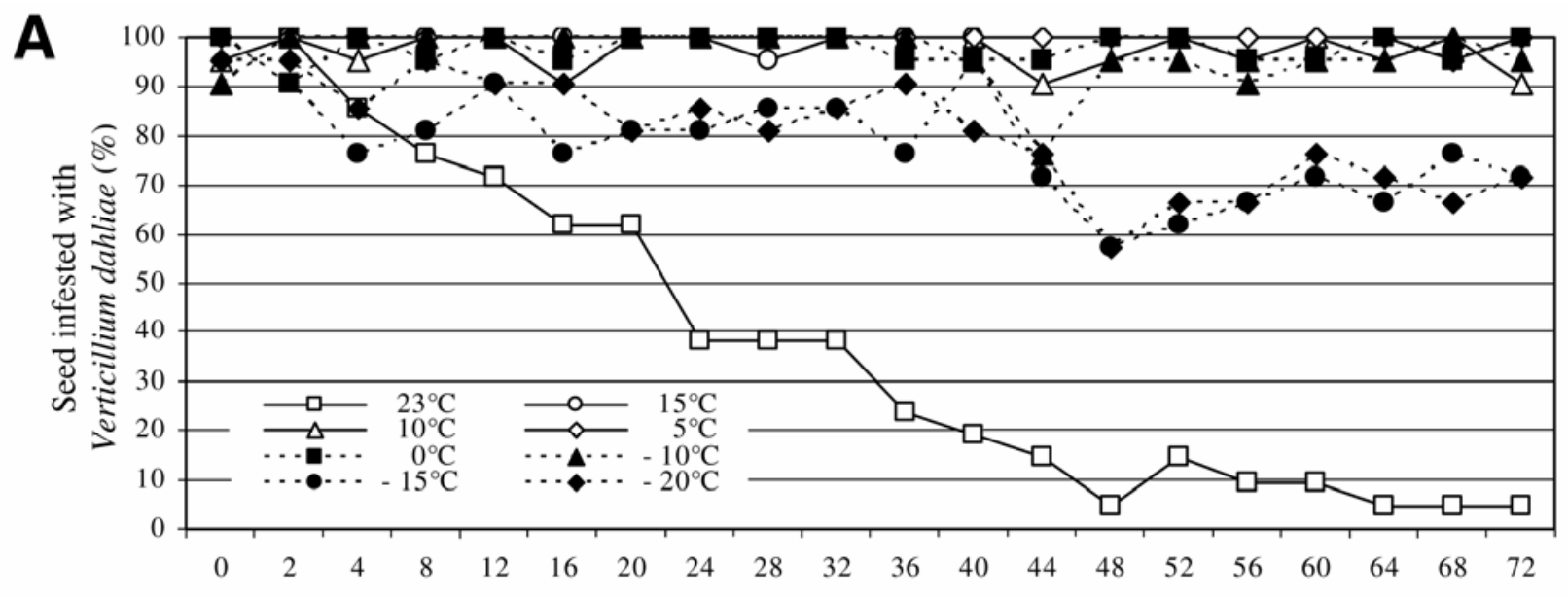

B

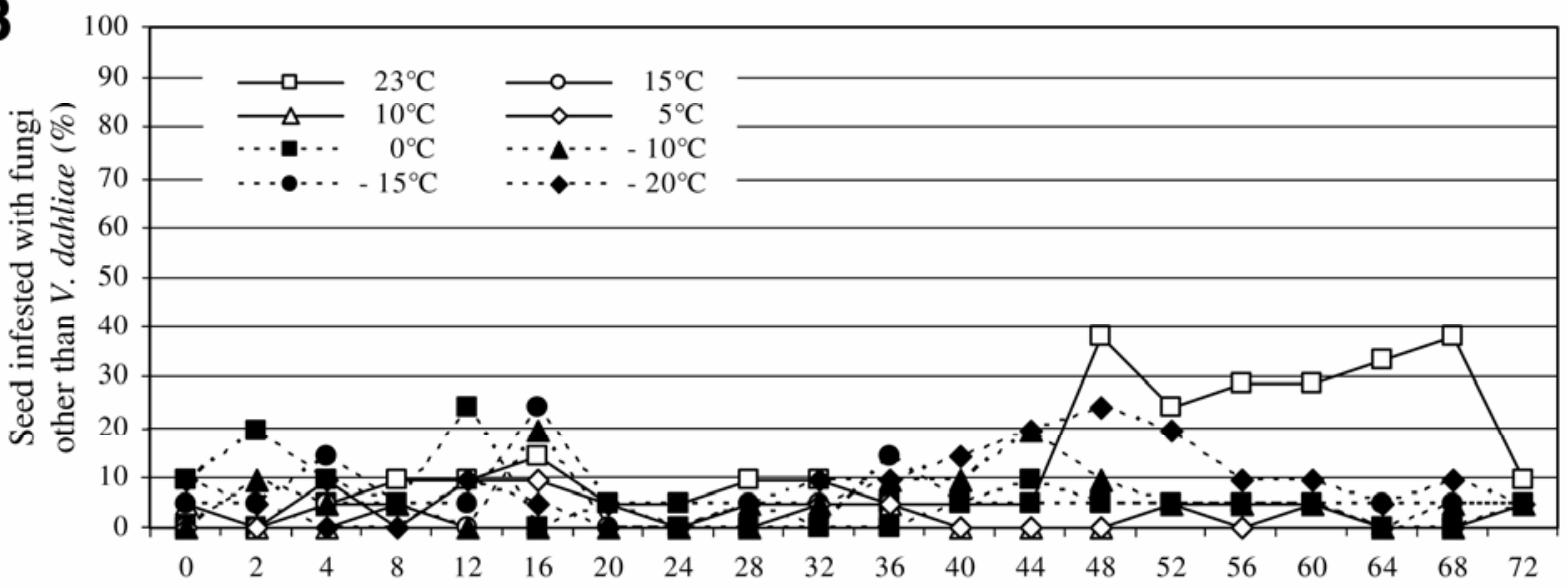

C

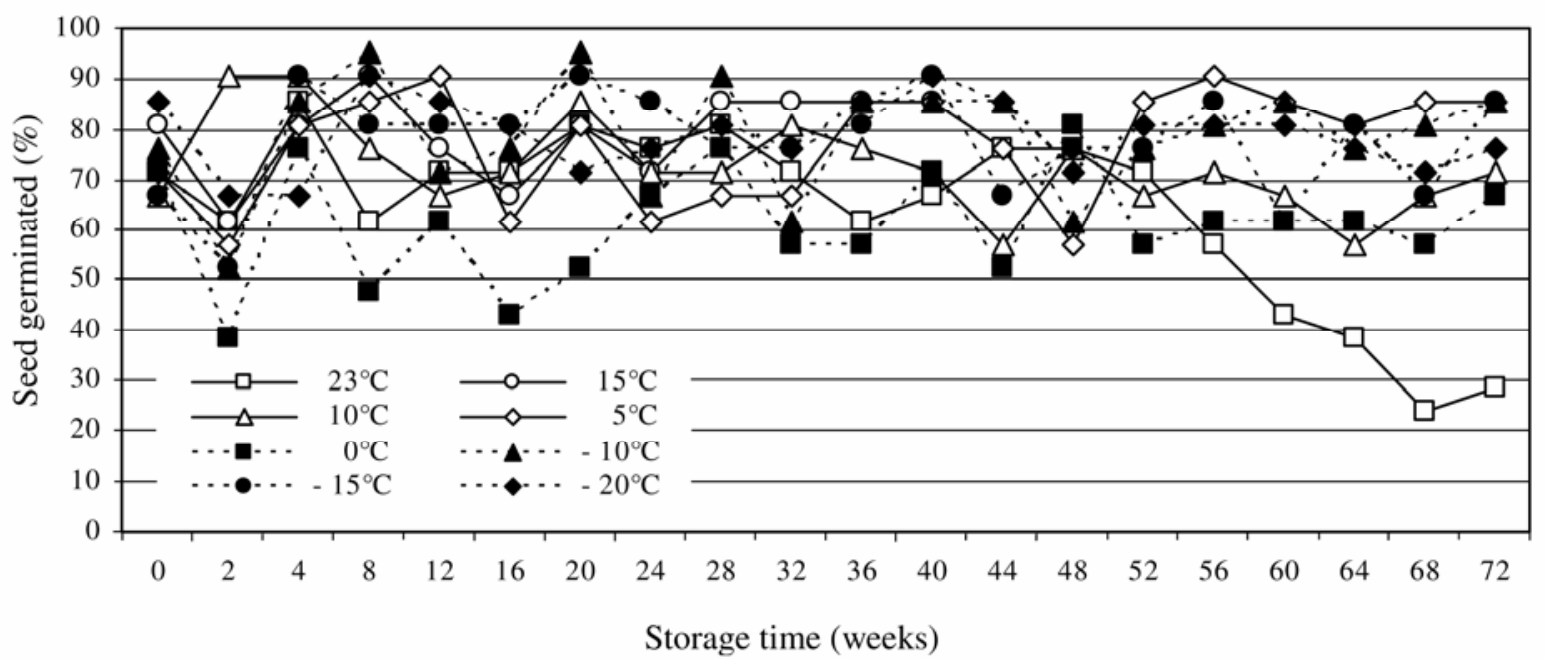

Fig. 2. Effect of storage temperature on the recovery of A, Verticillium dahliae and $\mathbf{B}$, other fungi, and $\mathbf{C}$, seed germination in seed lot 2. Over a 72 -week period, the percentage of sampled seed $(n=21)$ from seed lot 2 that exhibited colonies of $V$. dahliae and other fungi and germination was determined by plating seed onto a modified Sorenson's NP10 medium. Seed storage at $23^{\circ} \mathrm{C}$ was performed at ambient room temperature $\left( \pm 2^{\circ} \mathrm{C}\right)$, whereas other storage temperatures were performed in controlled incubators. Data collection for seed stored at $15^{\circ} \mathrm{C}$ was discontinued after 40 weeks due to an accidental exposure of the seed to water while in storage. 
months of storage at ambient conditions in an unheated facility in Manitoba, Canada. Allen (1) reported the survival of $V$. alboatrum in artificially infected seed of cotton for up to 8 months. Klisiewicz (11) found that the fungus remained viable in safflower seed for at least 2 years.

Prolonged storage at 15 to $-20^{\circ} \mathrm{C}$ did not reduce the seedborne incidence of $V$. dahliae in lettuce, but storage at room temperature $\left(23^{\circ} \mathrm{C}\right)$ for 20 weeks or longer did. However, there also was a corresponding decline in the viability of seed stored at room temperature. The drop in seed viability is not conclusive, because germination tests were not performed in a typical manner on germination paper, but rather on the same modified NP10 medium used to detect $V$. dahliae. However, it has been our experience that viable lettuce seed generally germinates within a week of being placed on the modified NP10 medium (G. E. Vallad and K. V. Subbarao, unpublished data).

Few studies have been reported for the effect of storage temperature on the survival of $V$. dahliae in seed and other plant materials. The prolonged storage of strawberry runner plants for 18 to 34 days at $1{ }^{\circ} \mathrm{C}$ was reported to reduce the recovery of $V$. dahliae in infected plants and the incidence of Verticillium wilt in the field following transplanting (27). Some success at eliminating $V$. dahliae from infested eggplant seed by treating with hot water at $49^{\circ} \mathrm{C}$ also has been reported (10). Future experiments should test the effect of higher storage temperatures and hot-water treatments on the survival of $V$. dahliae in lettuce seed.

Regardless of the virulence or host of origin, seed transmission of $V$. dahliae to seedlings of $L$. sativa leading to disease occurred under greenhouse conditions. The importance of seedborne inoculum in the dissemination of $V$. dahliae has been debated in the literature $(10,21,22,34)$. Even though seed transmission of $V$. dahliae was demonstrated in cotton (24), eggplant, and tomato (10), the work of Rudolph (21) and Rudolph and Harrison (22), while acknowledging that seed transmission was possible, argued that it was "improbable and of no economic significance" in California production due to the low incidence of disease they observed in controlled field trials. This debate over the importance of seedborne inoculum stems from the erratic nature of seed infestation and the differences in seed transmission observed in greenhouse and field studies, often attributed to variability in the environment (10,11,23-25). The biological implications of our studies need to be tested further under field conditions.

Although we have not directly tested for seed transmission of $V$. dahliae under field conditions, we were able to recover $V$. dahliae from seed of several symptomatic lettuce plants recovered from the field (data not shown). These lettuce plants were uprooted at harvest maturity from a field, transplanted to pots, and then maintained in a greenhouse for another 30 days until seed harvest. Seed from these plants yielded $V$. dahliae colonies when plated on NP10 medium. In the lettuce seed production areas of the San Joaquin Valley, CA and elsewhere, seed is threshed directly from the bolted plants in the field (33) and these seed have not been tested for $V$. dahliae recovery.

A preliminary survey suggested that several common weed species harbored $V$. dahliae. These weeds were collected from a field with a known history of Verticillium wilt of lettuce. Of the weeds collected that harbored $V$. dahliae, all were identified previously as symptomatic or asymptomatic carriers of $V$. dahliae $(6,7,15,19)$, with the exception of Solanum sarrachoides Sendtner (hairy nightshade). We not only observed foliar or root symptoms common to Verticillium wilt among plants of S. sarrachoides and Sonchus oleraceus (data not shown) but also isolated V. dahliae from seed of $S$. oleraceus (data not shown). Evans (6) concluded that S. oleraceus was a nonhost of $V$. dahliae because the infection was locally confined to plant roots that would often harbor fungal counts similar to susceptible hosts, but lacked the production of microsclerotia. Several reports state that both Capsella bursa-pastoris (L.) Medik and Senecio vulgaris are hosts of $V$. dahliae, but vary in regards to the extent of internal colonization and external symptoms $(4,8,35)$. Environmental and genotypic variation among geographic locations and host-pathogen interactions, respectively, likely explain the differences observed by previous researchers.

Further studies are required to determine the extent of $V$. dahliae among weed species in California. All of the weeds surveyed in this study that failed to recover $V$. dahliae were classified as susceptible by other researchers, except Polygonum lapathifolium L. (curlytop knotweed) and Conyza canadensis (L.) Cronq. (mare's tail) $(4,6,8,15,19,35)$. However, several other species of Polygonum, including $P$. pennsylvanicum L., P. convolvulus L., and $P$. persicaria L., previously were classified as hosts of $V$. dahliae (6-8). Several monocots, although generally regarded as nonhosts of $V$. dahliae, also have been reported to exhibit disease symptoms and to harbor localized populations of $V$. dahliae capable of forming microsclerotia $(8,13,14,16-18)$. Sixty other members of the family Asteraceae (Compositae) and 22 other members of the family Solanaceae are listed as known hosts of $V$. dahliae or V. albo-atrum (19); therefore, the addition of Solanum sarrachoides to the growing list of hosts is not surprising.

The susceptibility of several weed species to $V$. dahliae and the infestation of seed and subsequent infection of seedlings from these seed has the potential to spread the pathogen in coastal California. L. serriola (prickly lettuce) is broadly distributed throughout California and is a major weed commonly associated with lettuce production in the Salinas and Pajaro Valleys of central California. Although we did not sample any $L$. serriola plants during our surveys, several greenhouse experiments have demonstrated the susceptibility of $L$. serriola to lettuce isolates of $V$. dahliae (data not shown), stressing the importance of controlling these weeds in problematic growing areas, even when the afflicted fields are in rotation with another crop (like artichokes). The susceptibility of Lactuca spp. to isolates of $V$. dahliae from lettuce, in addition to the susceptibility of lettuce to several isolates of $V$. dahliae that were collected from weed species (including an isolate that was more virulent than the isolate from lettuce), raises concerns about the potential of weed species to act as a reservoir of $V$. dahliae in California vegetable production areas. Lettuce was not considered a host of $V$. dahliae until 1995, when a surprising outbreak of Verticillium wilt was observed in three lettuce fields totaling 20 ha in Watsonville, CA (33). Since 1995, Verticillium wilt has spread to 200 ha throughout the Salinas and Pajaro Valleys in Monterey and Santa Cruz Counties, CA. In greenhouse experiments, an isolate of $V$. dahliae from lettuce was pathogenic on nearly every vegetable produced in the area (2), severely limiting the practical use of crop rotations to control this disease. Now the additional finding of several weed species capable of harboring the pathogen adds an additional layer of complexity to this disease. Several other studies have shown that weed species are an important source of $V$. dahliae often neglected in epidemiological studies $(4,6,8,15,35)$. Evans $(5,6)$ found that several weed species, including Xanthium pungens $\mathrm{L}$. and $X$. spinosum $\mathrm{L}$. often harbored $V$. dahliae isolates pathogenic to cotton. More importantly, these Xanthium spp. could produce seedborne inoculum that Evans (6) hypothesized could explain the association between the spread of weed hosts and the spread of Verticillium wilt of cotton throughout the Namoi Valley of New South Wales, Australia $(5,6)$. Our studies demonstrate that similar factors, seed transmission and weed hosts, are in place in the Salinas Valley and could be partially responsible for the spread of $V$. dahliae throughout the area, in addition to other mechanisms of spread induced by wind and various human activities. Future research should clarify the roles of weedborne and seedborne inoculum in the epidemiology of Verticillium wilt under field conditions.

\section{LITERATURE CITED}

1. Allen, R. M. 1951. Cotton seeds are capable of carrying Verticillium. Plant Dis. Rep. 35:11-12. 
2. Bhat, R. G., and Subbarao, K. V. 1999. Host range specificity in Verticillium dahliae. Phytopathology 89:1218-1225.

3. Bhat, R. G., and Subbarao, K. V. 2003. Characterization of Verticillium dahliae isolates and wilt epidemics of pepper. Plant Dis. 87:789-797.

4. Busch, L. V., Smith, E. A., and Njoh-Elango, F. 1978. The effect of weeds on the value of rotation as a practical control for Verticillium wilt of potato. Can. Plant Dis. Surv. 58:61-64.

5. Evans, G. 1968. Infection of Xanthium pungens by seed-borne Verticillium dahliae. Plant Dis. Rep. 52:976-978.

6. Evans, G. 1971. Influence of weed hosts on the ecology of Verticillium dahliae in newly cultivated areas of the Namoi Valley, New South Wales. Ann. Appl. Biol. 67:169-175.

7. Harrison, J. A. C., and Isaac, I. 1969. Survival of the causal agents of early dying disease (Verticillium wilt) of potatoes. Ann. Appl. Biol. 63:277-288.

8. Johnson, W. M., Johnson, I. K., and Brinkerhoff, I. A. 1980. Symptomatology and formation of microsclerotia in weeds inoculated with Verticillium dahliae from cotton. Phytopathology 70:31-35.

9. Kabir, Z., Bhat, R. G., and Subbarao, K. V. 2004. Comparison of media components for recovery of Verticillium dahliae from soil. Phytopathology 88:49-55.

10. Kadow, K. J. 1934. Seed transmission of Verticillium wilt of eggplants and tomatoes. Phytopathology 24:1265-1268.

11. Klisiewicz, J. M. 1975. Survival and dissemination of Verticillium in infected safflower seed. Phytopathology 65:696-698.

12. Koike, S. T., Subbarao, K. V., Davis, R. M. Gordon, T. R., and Hubbard, J. C. 1994. Verticillium wilt of cauliflower in California. Plant Dis. 78:1116-1121.

13. Krikun, J., and Bernier, C. C. 1990. Morphology of microsclerotia of Verticillium dahliae in roots of gramineous plants. Can. J. Plant Pathol. 12:439-441.

14. Lacy, M. L., and Horner, C. E. 1966. Behavior of Verticillium dahliae in the rhizosphere and on roots of plants susceptible, resistant, and immune to wilt. Phytopathology 56:427-430.

15. Ligoxigakis, E. K., Vakalounakis, D. J., and Thanassoulopoulos, C. C. 2002. Weed hosts of Verticillium dahliae in Crete: Susceptibility, symptomatology and significance. Phytoparasitica 30:511-518.

16. Malik, N. K., and Milton, J. M. 1980. Survival of Verticillium in Monocotyledonous plants. Trans. Br. Mycol. Soc. 75:496-497.

17. Martinson, C. A., and Horner, C. E. 1962. Importance of nonhosts in maintaining the inoculum potential of Verticillium. (Abstr.) Phytopathology 52:742.

18. Mathre, D. E. 1989. Pathogenicity of an isolate of Verticillium dahliae from barley. Plant Dis. 73:164-167.

19. Pegg, G. F., and Brady, B. L. 2002. Verticillium Wilts. CABI Publishing, New York.

20. Pullman, G. S., and DeVay, J. E. 1982. Epidemiology of Verticillium wilt of cotton: a relationship between inoculum density and disease progression. Phytopathology 72:549-554.

21. Rudolph, B. A. 1944. The unimportance of tomato seed in the dissemination of Verticillium wilt in California. Phytopathology 34:622-630.

22. Rudolph, B. A., and Harrison, G. J. 1944. The unimportance of cotton seed in the dissemination of Verticillium wilt in California. Phytopathology 34:840-860.

23. Sackston, W. E. 1980. Some factors influencing infection of sunflower seed by Verticillium dahliae. Can. J. Plant Pathol. 2:209-212.

24. Sackston, W. E., and Martens, J. W. 1959. Dissemination of Verticillium albo-atrum on seed of sunflower (Helianthus annuus). Can. J. Bot. 37:759-768.

25. Schippers, B., and Schermer, A. K. F. 1966. Effect of antifungal properties of soil on dissemination of the pathogen and seedling infection originating from Verticillium-infected achenes of Senecio. Phytopathology 56:549552.

26. Schuster, M. L., and Nuland, D. S. 1960. Seed transmission of safflower Verticillium wilt fungus. Plant Dis. Rep. 44:901-903.

27. Shaw, D. V., Gordon, T. R., and Larson, K. D.
2002. Runner plant cold storage reduces Verticillium dahliae infection of nursery origin in strawberry. HortScience 37:932-935.

28. Smith, H. C. 1965. The morphology of Verticillium albo-atrum, V. dahliae, and V. tricorpus. N. Z. J. Agric. Res. 8:450-478.

29. Snyder, W. C., and Wilhelm, S. 1962. Seed transmission of Verticillium wilt of spinach. (Abstr.) Phytopathology 52:365

30. Sorensen, L. H., Schneider, A. T., and Davis, J. R. 1991. Influence of sodium polygalacturonate sources and improved recovery of Verticillium spp. from soil. (Abstr.) Phytopathology $81: 1347$.

31. Subbarao, K. V. 2002. Biology and epidemiology of Verticillium wilt of lettuce. Pages 154 161 in: Annual Report of the California Lettuce Research Board for April 1, 2001 through March 31, 2002. California Lettuce Research Board, Salinas, CA

32. Subbarao, K. V., Chassot, A., Gordon, R. R., Hubbard, J. C., Bonello, P., Mullin, R., Okamoto, D., Davis, R. M., and Koike, S. T. 1995. Genetic relationships and cross pathogenicities of Verticillium dahliae isolates from cauliflower and other crops. Phytopathology $85: 1105-1112$.

33. Subbarao, K. V., Hubbard, J. C., Greathead, A. S., and Spencer, G. A. 1997. Verticillium wilt Pages 26-27 in: Compendium of Lettuce Diseases. R. M. Davis, K. V. Subbarao, R. N. Raid, and E. A. Kurtz, eds. The American Phytopathological Society, St. Paul, MN.

34. Taubenhaus, J. J. 1936. Verticillium wilt of cotton. Page 111 in: Texas Agricultural Experiment Station 49th Annual Report, Lubbock, TX.

35. Vargas-Machuca, R., Martin, C., and Galindez, W. 1987. Recovery of Verticillium dahliae from weed plants in farmers' fields in Peru. Plant Dis. 71:756-758

36. Wilhelm, S. 1955. Longevity of the Verticillium wilt fungus in the laboratory and field. Phytopathology 45:180-181.

37. Zimmer, D. E. 1962. Verticillium wilt of safflower in the United States-A potential problem. Plant Dis. Rep. 46:665-666. 